\title{
PENGARUH GAYA KEPEMIMPINAN TERHADAP KINERJA KARYAWAN PADA LEMBAGA "BUMI DAMAI" DESA KUWIRAN KECAMATAN KARE KABUPATEN MADIUN
}

\author{
Ninik Srijani \\ Dosen Prodi Pendidikan Ekonomi IKIP PGRI Madiun \\ Mahasiswa S3 Ilmu Ekonomi Universitas Merdeka Malang
}

\begin{abstract}
The purpose of this study was to influence of leadership style on employee performance in institution Bumi Damai Madiun. The sample in this study all existing employees in the institution Bumi Damai Madiun, totaling 34 people. Data collection using questionnaires. In analyzing the data used statistical methods to test the product moment correlation is valid whether or not the instruments used and the method of regression tests for testing the hypothesis put forward in this study.
\end{abstract}

The results showed that leadership style has relationships and a positive influence on the performance of employees at the Institute Bumi Damai Madiun. It is obtained from the correlation test that shows the value of rhitung is rtabel 0.339 0.740 whereas, on the other hand is 0.000 while the magnitude Sighit Sigprob 0.05 . This means that the value rhitung $\geq$ rtabel $(0.740 \geq 0.339)$ or $\leq$ Sighit Sigprob $(0.000 \leq 0.05)$ meaning a rejection of HO to show that leadership style has a relationship with employee performance on Institute Bumi Damai Madiun. Further test results were also obtained Fisher, Fhitung value is 38.843 while the F table at 4.149, on the other hand is 0.000 while the magnitude Sighit Sigprob 0.05. This means that the value Fcount Ftabel $\geq(\geq$ $38.8434 .149)$ or $\leq$ Sighit Sigprob $(0.000 \leq 0.05)$ meaning a rejection of HO which indicates that there is the influence of leadership style on the performance of employees at the Institute Bumi Damai Madiun. Besides t test results obtained, is 6.232 whereas tcount ttabel of 2.037, on the other hand is 0.000 while the value Sighit Sigprob 0.05. This means that tcount $\geq$ TTable $(6.232 \geq 1.694)$ or $\leq$ Sighit Sigprob $(0.000 \leq 0.05)$ meaning a rejection of $\mathrm{HO}$ which shows that there are different leadership style influence on the performance of employees at the Institute Bumi Damai Madiun. $R 2$ of 0.548 results showed that $54.8 \%$ of employees affected by the performance variable leadership style, while the remaining $45.2 \%$ is influenced by other factors.

Keywords: Leadership Style, Employee Performance.

\section{Pendahuluan}

Keberhasilan suatu organisasi ditentukan dari sumber daya manusia yang ada di dal;amnya. Dalam rangka pengembangan sumber daya manusia sebagai arah dan tujuan suatu organisasi sudah seharusnya mendapat perhatian yang sungguh-sungguh. Keberhasilan upaya pengembangan sumber daya manusia yang berkualitas juga tidak lepas dari pengaruh kualitas seorang pemimpin. 
Menurut Saydam (2005:703) disebut apa orang yang melaksanakan tugas kepemimpinan itu? Orang yang melaksanakan atau diserahi tugas-tugas kepemimpinan biasanya disebut pemimpin (leader) atau manajer. Dengan demikian, tugas-tugas kepemimpinan ini dapat berlaku atau ditemui dimana saja dan dalam situasi apa saja, yang tidak tergantung pada struktur atau pengangkatan secara resmi. Ia dapat ditemui baik dalam organisasi yang sudah teratur rapi, maupun dalam situasi darurat atau dalam keadaan tidak normal.

Oleh karena itu, gaya kepemimpinan sangatlah penting untuk diterapkan manajer dalam mengatur bawahannya. Gaya dan style hidupnya ini pasti akan mewarnai perilaku dan tipe kepemimpinannya.

Menurut Sastrohadiwiriyo (2005:290) dari beberapa kasus (absteeinsm), terjadinya kemangkiran yang berlebihan pada diri tenaga kerja merupakan dampak kurang taatnya pada asas pedoman formatif, atau kurangnya pengertian dan kesadaran diri tenaga kerja betapa pentingnya masuk kerja secara teratur. Untuk memperbaiki hal-hal yang dianggap kurang sesuai dengan pedoman normatif yang berlaku manajer yang bijaksana akan memberikan peringatan, penskoran tanpa kompensasi dan pemberhentian hubungan kerja untuk hal yang sangat drastis dan spontanitas.

Kepemimpinan berperan sebagai penggerak segala sumber daya manusia dan sumber lain yang ada dalam organisasi. Dalam kehidupan organisasi gaya kepemimpinan mempunyai kedudukan yang vital, sebab perubahan perilaku bawahan sangat ditentukan oleh gaya kepemimpinan yang diterapkan. Gaya kepemimpinan yang tepat akan memberikan dorongan timbulnya kesediaan bawahan untuk berperilaku dan berbuat sesuai dengan apa yang dikehendaki pimpinan. Gaya kepemimpinan yang tampil sebagai perilaku dan perbuatan yang ditujukan kearah lingkungan kerjanya, baik tugas pekerjaan, kebijaksanaan dan prosedur, serta hubungan antar manusia guna meningkatkan kualitas kinerja karyawan. Dengan gaya kepemimpinan yang sesuai dengan kondisi organisasi dan lingkungan perusahaan diharapkan mampu meningkatkan kinerja karyawan.

Menurut R.Terry (dalam Saydam, 2005:700) "kepemimpinan adalah keseluruhan kegiatan (aktivitas) untuk mempengaruhi kemauan orang lain untuk mencapai tujuan bersama." Sedangkan menurut Saydam (2005:702) sendiri, "kepemimpinan merupakan kemauan lebih yang dimiliki oleh seseorang (baik dalam organisasi atau tidak) untuk mempengaruhi orang-orang yang ada dilingkungannya, agar mereka bersedia bekerja untuk mencapai tujuan yang diinginkan pemimpin." 
Menurut Stoner (dalam Handoko, 2003:294) "kepemimpinan manajerial dapat didefinisikan sebagai suatu proses pengarahan dan pemberian pengaruh pada kegiatan-kegiatan pada sekelompok anggota yang saling berhubungan tugasnya."

Ada tiga implikasi penting dari definisi ini. Pertama, kepemimpinan menyangkut orang lain, bawahan atau pengikut. Kedua, kepemimpinan menyangkut suatu pembagian kekuasaan yang tidak seimbang antara pemimpin dan anggota kelompok. Ketiga, selain dapat memberikan pengarahan kepada para bawahan atau pengikut, pemimpin dapat juga menggunakan pengaruh.

Sedangkan menurut Hamalik (2007:167) "gaya kepemimpinan adalah menunjuk pada sikap, cara, penampilan kepemimpinan.” Dari gaya kepemimpinannya itulah pemimpin akan memiliki karakteristiknya sendiri.

Jadi, kepemimpinan adalah kemampuan seseorang untuk mengarahkan bawahannya agar bertanggung jawab dalam menjalankan tugas-tugasnya. Sedangkan gaya kepemimpinan adalah cara yang digunakan oleh seorang pemimpin itu sendiri dan merupakan ciri khas dari kepemimpinannya.

Di lain pihak Mangkunegara (2005: 9) menyatakan bahwa kinerja karyawan adalah prestasi kerja ataupun hasil kerja (output) baik kualitas maupun kuantitas yang dicapai karyawan persatuan periode waktu dalam melaksanakan tugas kerjanya sesuai dengan tanggung jawab yang diberikan kepadanya.

Dalam mewujudkan fungsi-fungsi kepemimpinan secara integral sebagaimana telah dikemukakan terdahulu akan berlangsung aktivitas gaya kepemimpinan dengan polanya masing-masing. Seorang pemimpin mempunyai sifat, kebiasaan, temperamen, watak, dan kepribadian sendiri yang unik khas sehingga tingkah laku gayanya yang membedakan dirinya dengan orang lain. Kepemimpinan merupakan kemampuan seseorang untuk mengarahkan bawahannya agar bertanggung jawab dalam menjalankan tugas-tugasnya. Sedangkan gaya kepemimpinan adalah cara yang digunakan oleh seorang pemimpin itu sendiri dan merupakan ciri khas dari kepemimpinannya.

Pada dasarnya gaya kepemimpinan seseorang berpengaruh dalam upaya meningkatkan kinerja karyawan. Apabila didalam sebuah perusahaan terjadi gaya kepemimpinan yang kurang sesuai dengan situasi dan kondisi perusahaan, hal ini tentu akan sangat mempengaruhi kinerja karyawan di perusahaan. Salah satu hal 
yang menyebabkan baik buruknya kinerja karyawan akan dipengaruhi oleh pengaruh dari gaya pemimpinnya itu sendiri. Seorang pemimpin merupakan panutan bagi bawahannya. Setiap gerak gerik tingkah lakunya akan sangat berdampak terhadap sikap dan perbuatan bawahannya pula. Sehingga seorang manajer diharapkan memiliki gaya kepemimpinan yang baik yang nantinya akan berpengaruh positif pula terhadap disiplin kerja karyawannya.

\section{Metode Penelitian}

Tempat penelitian dilaksanakan di Lembaga Bumi Damai Desa Kuwiran, Kecamatan Kare Kabupaten Madiun. Rancangan penelitian yang digunakan dalam penelitian ini adalah penelitian kausal-komparatif. Tujuan penelitian kausalkomparatif adalah untuk menyelidiki kemungkinan hubungan kausal atau sebabakibat berdasarkan atas pengamatan terhadap akibat yang ada. Ciri-ciri penelitian kausal-komparatif adalah bersifat ex post facto artinya data dikumpulkan setelah semua kejadian yang akan diteliti berlangsung (Usman dan Abdi, 2009: 35).

Rancangan penelitian dapat dilihat pada gambar sebagai berikut:

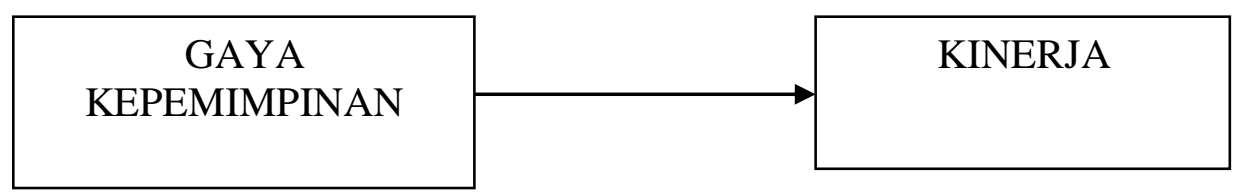

\section{Gambar Rancangan Penelitian}

Dalam penelitian ini yang menjadi variabel bebas $(\mathrm{X})$ adalah Gaya Kepemimpinan dan variabel terikat (Y) adalah kinerja karyawan.

Dalam penelitian ini yang menjadi populasi adalah seluruh karyawan pengasuh Lembaga Bumi Damai Madiun sebanyak 34 Orang. Teknik pengumpulan data yang digunakan dalam penelitian ini adalah Teknik Angket. Jumlah soal dalam kuesioner ini adalah 20 butir soal yang dibagi dalam 2 variabel, dengan perincian 10 soal untuk variabel gaya kepemimpinan $(\mathrm{X})$ dan 10 soal yang lain untuk variabel kinerja karyawan (Y). 


\section{Hasil Penelitian}

A. Variabel Gaya Kepemimpinan

Deskripsi dari variabel Gaya kepemimpinan dengan jumlah data $(\mathrm{N})$ sebanyak 34 mempunyai deskripsi data sebagai berikut: (a) jumlah skor total sebesar 1278; (b) nilai rata-rata hitung (mean) sebesar 37,59; (c) median sebesar 38,00; (d) modus sebesar 38; (e) standar deviasi sebesar 4,633; (f) nilai minimum sebesar 27; ( $\mathrm{g}$ ) nilai maximum sebesar 46.

B. Variabel Kinerja karyawan

Deskripsi dari variabel kinerja karyawan dengan jumlah data $(\mathrm{N})$ sebanyak 34 mempunyai deskripsi data sebagai berikut: (a) jumlah skor total sebesar 1262; (b) nilai rata-rata hitung (mean) sebesar 37,12; (c) median sebesar 38,00; (d) modus sebesar 40; (e) standar deviasi sebesar 4,643; (f) nilai minimum sebesar 30; (g) nilai maximum sebesar 48 .

C. Hasil Uji Korelasi

Hasil uji korelasi didapat besarnya nilai $\mathrm{r}_{\text {hitung }}$ adalah 0,740 sedangkan $\mathrm{r}_{\text {tabel }}$ 0,339, dilain pihak besarnya Sighit adalah 0,000 sedangkan Sig prob 0,05. Hal ini berarti bahwa nilai $\mathrm{r}_{\text {hitung }} \geq \mathrm{r}_{\text {tabel }}(0,740 \geq 0,339)$ atau $\operatorname{Sig}_{\text {hit }} \leq \operatorname{Sig}_{\text {prob }}$ $(0,000 \leq 0,05)$. Atas dasar uji korelasi tersebut dapat disimpulkan bahwa $\mathrm{H}_{0}$ ditolak, artinya ada hubungan gaya kepemimpinan dengan kinerja karyawan pada Lembaga Bumi Damai Madiun. Dilain pihak dalam uji determinasi diperoleh nilai $\mathrm{R}^{2}$ ( $\mathrm{R}$ Square) atau koefisien determinasi yang digunakan untuk mengetahui seberapa besar prosentase sumbangan gaya kepemimpinan terhadap kinerja karyawan nilai $\mathrm{R}^{2}$ adalah 0,548 . Jadi sumbangan pengaruh dari gaya kepemimpinan terhadap kinerja karyawan yaitu 54,8\% sedangkan sisanya sebesar $45,2 \%$ dipengaruhi oleh faktor lain

\section{Uji Fisher}

Dari hasil Uji Fisher diperoleh besarnya nilai $F_{\text {hitung }}$ adalah 38,843 sedangkan $F_{\text {tabel }}$ sebesar 4,149, dilain pihak besarnya Sighit adalah 0,000

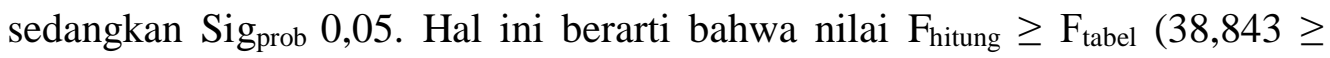
$4,149)$ atau $\operatorname{Sig}_{\text {hit }} \leq \operatorname{Sig}_{\text {prob }}(0,000 \leq 0,05)$. Atas dasar uji Fisher tersebut dapat 
disimpulkan bahwa $\mathrm{H}_{0}$ ditolak, artinya ada pengaruh gaya kepemimpinan terhadap kinerja karyawan pada Bumi Damai Madiun.

Selain digunakan untuk mencari pengaruh, uji Fisher atau Anova bisa juga digunakan untuk menguji linearitas. Karena $F_{\text {hitung }}$ sebesar $38,843 \geq F_{\text {tabel }}$ sebesar 4,149, berarti ada hubungan yang linier antara variabel gaya kepemimpinan dengan kinerja karyawan.

\section{E. Uji t}

\section{Coefficients $^{\mathrm{a}}$}

\begin{tabular}{|c|c|c|c|c|c|}
\hline \multirow{2}{*}{ Model } & \multicolumn{2}{|c|}{$\begin{array}{c}\text { Unstandardized } \\
\text { Coefficients }\end{array}$} & $\begin{array}{c}\text { Standardized } \\
\text { Coefficients }\end{array}$ & \multirow{2}{*}{$\mathrm{T}$} & Sig. \\
\cline { 2 - 5 } & B & Std. Error & Beta & \\
\hline (Constant) & 9.220 & 4.509 & & 2.045 & .049 \\
pelatihankerja & .742 & .119 & .740 & 6.232 & .000 \\
\hline
\end{tabular}

a. Dependent Variable: kinerjakaryawan

Atas dasar tabel di atas dapat dibuat persamaan garis regresi sebagai berikut: $\mathrm{Y}=9,220+0,742 \mathrm{X}$, artinya adalah apabila gaya kepemimpinan ditingkatkan satu kali akan terjadi kenaikan kinerja karyawan sebanyak $0,742 \%$, apabila faktor yang lainnya tetap. Dari hasil perhitungan diperoleh nilai $t_{\text {hitung }}$ adalah 6,232 sedangkan $\mathrm{t}_{\text {tabel }}$ sebesar 2,037, dilain pihak nilai $\mathrm{Sig}_{\text {hit }}$

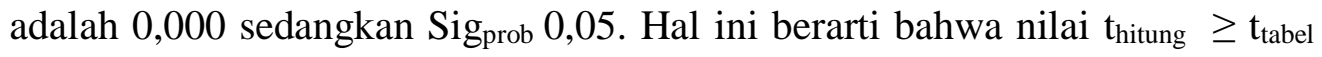
$(6,232 \geq 2,037)$ atau $\operatorname{Sig}_{\text {hit }} \leq \operatorname{Sig}_{\text {prob }}(0,000 \leq 0,05)$. Atas dasar uji t tersebut dapat disimpulkan bahwa $\mathrm{H}_{0}$ ditolak, artinya ada beda pengaruh gaya kepemimpinan terhadap kinerja karyawan pada Lembaga Bumi Damai Madiun 


\section{Simpulan Hasil Analisis}

Atas dasar hasil pengujian hipotesis dapat diambil simpulan sebagai berikut.

1. Simpulan Uji Korelasi

Hasil dari pengujian korelasi dapat diperoleh besarnya nilai $\mathrm{r}_{\text {hitung }}$ adalah 0,740 sedangkan $r_{\text {tabel }} 0,339$, dilain pihak besarnya $\operatorname{Sig}$ hit adalah 0,000 sedangkan $\operatorname{Sig}_{\text {prob }} 0,05$. Hal ini berarti bahwa nilai $r_{\text {hitung }} \geq r_{\text {tabel }}(0,740 \geq$ 0,339) atau $\operatorname{Sig}_{\text {hit }} \leq \operatorname{Sig}_{\text {prob }}(0,000 \leq 0,05)$. Selain itu diperoleh nilai $R^{2}$ adalah 0,548. Jadi sumbangan pengaruh dari gaya kepemimpinan terhadap kinerja karyawan yaitu $54,8 \%$.

Sesuai hipotesis yang diajukan dapat diperoleh simpulan bahwa ada hubungan gaya kepemimpinan dengan kinerja karyawan pada Lembaga Bumi Damai Madiun. Berarti $\mathrm{H}_{0}$ ditolak, dan $\mathrm{H} 1$ diterima.

2. Simpulan Uji Fisher

Hasil dari pengujian Fisher dengan uji Anova dapat diperoleh nilai

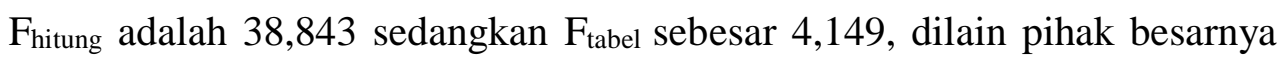
$\mathrm{Sig}_{\text {hit }}$ adalah 0,000 sedangkan $\mathrm{Sig}_{\text {prob }}$ 0,05. Hal ini berarti bahwa nilai $\mathrm{F}_{\text {hitung }}$ $\geq F_{\text {tabel }}(38,843 \geq 4,149)$ atau $\operatorname{Sig}_{\text {hit }} \leq \operatorname{Sig}_{\text {prob }}(0,000 \leq 0,05)$. Sesuai hipotesis yang diajukan dapat diperoleh simpulan bahwa ada pengaruh gaya kepemimpinan terhadap kinerja karyawan pada Lembaga Bumi Damai Madiun. Berarti $\mathrm{H}_{0}$ ditolak, $\mathrm{H} 1$ diterima.

3. Simpulan Uji $\mathrm{t}$

Dari hasil perhitungan atau pengujian yang dilakukan diperoleh persamaan regresi sebagai berikut: $\mathrm{Y}=9,220+0,742 \mathrm{X}$, simpulannya adalah apabila gaya kepemimpinan ditingkatkan satu kali akan terjadi kenaikan kinerja karyawan sebanyak 0,742\%, apabila faktor yang lainnya tetap. Hasil dari uji t dapat diperoleh nilai thitung adalah 6,232 sedangkan $\mathrm{t}_{\text {tabel }}$ sebesar 2,037, dilain pihak nilai Sighit adalah 0,000 sedangkan Sig 0,05. Hal ini berarti bahwa nilai $t_{\text {hitung }} \geq t_{\text {tabel }}(6,232 \geq 2,037)$ atau Sig $_{\text {hit }} \leq$ $\operatorname{Sig}_{\text {prob }}(0,000 \leq 0,05)$. Sesuai hipotesis yang diajukan dapat diperoleh simpulan bahwa ada beda pengaruh gaya kepemimpinan terhadap kinerja karyawan pada Lembaga Bumi Damai Madiun. Berarti $\mathrm{H}_{0}$ ditolak, H1 diterima. 


\section{Penutup}

Hasil penelitian menunjukkan bahwa gaya kepemimpinan berpengaruh terhadap kinerja karyawan. Hal ini menunjukkan bahwa gaya kepemimpinan yang baik adalah gaya kepemimpinan yang diterima oleh semua karyawannya artinya karyawan dalam bekerja mempunyai atasan yang gaya kepemimpinan sesuai dengan kemauan karyawan sehingga dapat meningkatkan kualitas kinerja karyawannya.

Selanjutnya adalah pembahasan untuk uji regresi (uji korelasi, uji Fisher, dan uji t):

1. Pembahasan Uji Korelasi

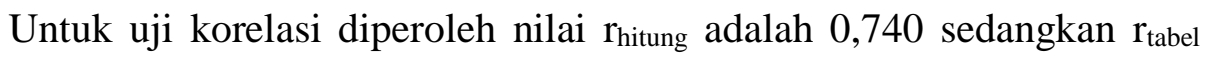
0,339, dilain pihak besarnya $\operatorname{Sig}_{\text {hit }}$ adalah 0,000 sedangkan $\operatorname{Sig}_{\text {prob }}$ 0,05. Hal ini berarti bahwa nilai $r_{\text {hitung }} \geq r_{\text {tabel }}(0,740 \geq 0,339)$ atau $\operatorname{Sig}_{\text {hit }} \leq \operatorname{Sig}_{\text {prob }}(0,000 \leq$ 0,05). Dengan demikian $\mathrm{H}_{0}$ ditolak, artinya ada hubungan gaya kepemimpinan dengan kinerja karyawan pada Lembaga Bumi Damai Madiun.

Nilai $\mathrm{R}^{2}$ yang diperoleh adalah sebesar $54,8 \%$. Menunjukkan bahwa gaya kepemimpinan mempengaruhi kinerja karyawan sebanyak 54,8\%.

2. Pembahasan Uji Fisher

Untuk uji Fisher diperoleh nilai $F_{\text {hitung }}$ adalah 38,843 sedangkan $F_{\text {tabel }}$ sebesar 4,149, dilain pihak besarnya $\mathrm{Sig}_{\text {hit }}$ adalah 0,000 sedangkan Sig prob 0,05. Hal ini berarti bahwa nilai $F_{h i t u n g} \geq F_{\text {tabel }}(38,843 \geq 4,149)$ atau $\operatorname{Sig}_{\text {hit }} \leq$ $\operatorname{Sig}_{\text {prob }}(0,000 \leq 0,05)$. Dengan demikian $\mathrm{H}_{0}$ ditolak, artinya ada pengaruh gaya kepemimpinan terhadap kinerja karyawan pada Lembaga Bumi Damai Madiun.

3. Pembahasan Uji t

Dapat dilihat pada hasil persamaan regresi $\mathrm{Y}=9,220+0,742 \mathrm{X}$. Artinya apabila gaya kepemimpinan ditingkatkan satu kali akan terjadi kenaikan kinerja karyawan sebanyak $0,742 \%$, apabila faktor yang lainnya tetap. Untuk uji $\mathrm{t}$ diperoleh nilai thitung adalah 6,232 sedangkan $\mathrm{t}_{\text {tabel }}$ sebesar 2,037, dilain pihak nilai Sighit adalah 0,000 sedangkan Sig prob 0,05. Hal ini berarti bahwa nilai $t_{\text {hitung }} \geq t_{\text {tabel }}(6,232 \geq 2,037)$ atau $\operatorname{Sig}_{\text {hit }} \leq \operatorname{Sig}_{\text {prob }}(0,000 \leq$ 0,05). Dengan demikian $\mathrm{H}_{0}$ ditolak, artinya ada beda pengaruh gaya kepemimpinan terhadap kinerja karyawan pada Lembaga Bumi Damai 
Madiun. Dari hasil penelitian menunjukkan bahwa gaya kepemimpinan mempunyai hubungan sekaligus pengaruh terhadap kinerja karyawan. Artinya gaya kepemimpinan yang diterapkan oleh manager kepada karyawan akan menjadikan kinerja karyawannya meningkat.

\section{DAFTAR PUSTAKA}

Anwar, A. A. Prabu Mangkunegara. 2005. Evaluasi Kinerja SDM. Bandung: Refika Aditama.

Edy Sutrisno. 2010. Manajemen Sumberdaya Manusia. Jakarta: KENCANA MEDIA GROUP

Gauzali Saydam.2005. Manajemen Sumber Daya Manusia. Jakarta: Djambatan Grafindo Persada

I Komang Ardana, Ni Wayan Mujiati dan I Wayan Mudiartha Utama. 2012. Manajemen Sumber Daya Manusia. Yogyakarta: Graha Ilmu.

Kartini Kartono. 2008. Pemimpin dan Kepemimpinan. Jakarta : PT.Raja Grafindo Persada

M.N.Nasution. 2001. Manajemen Mutu Terpadu. Jakarta: Ghalia Indonesia

Malayu Hasibuan.2008.Manajemen Sumber Daya Manusia.Jakarta :PT Bumi Aksara

Marihot AMH Manullang. 2006. Manajemen Personalia. Yogyakarta: Gadjah Mada University Press.

Mohamad Mahsun. 2006. Pengukuran Kinerja Sektor Publik. Yogyakarta: BPFEYogyakarta.

Muchdarsyah Sinungan. 2005. Produktivitas Apa dan Bagaimana. Jakarta: Bumi Aksara

Oemar Hamalik. 2007. Manajemen Pelatihan Ketenagakerjaan Pedekatan Terpadu. Jakarta: Bumi Aksara

Rosita.2010.Definisi dan Ruang Lingkup Hukum Perusahaan. (http://rosita.staff.uns.ac.id/2010/07/definisi-dan-ruang-lingkuphukum-perusahaan/ Diunduh 13 Pebruari 2012).

Siswanto Sastrohadiwiriyo. 2005. Manajemen Tenaga Kerja Indonesia. Jakarta: Bumi Aksara

Sjafri Mangkuprawira. 2009. Bisnis, Manajemen dan Sumberdaya Manusia. Bogor: IPB Press

Sunarto dan Sahedhy, R Noor. 2003. Manajemen Sumber Daya Manusia. Yogyakarta: BPFE-UST Yogyakarta. 
Suwatno dan Doni Priansa. 2011. Manajemen SDM Dalam Organisasi Publik dan Bisnis. Bandung: Alfabeta.

T.Hani Handoko. 2011. Manajemen Personalia dan Sumberdaya Manusia. Yogyakarta: BPFE

Usman Rianse. 2009. Metodologi Penelitian Sosial dan Ekonomi (Teori dan Aplikasi). Bandung: ALFABETA

Vaithzal Rivai, dkk. 2009. Manajemen Sumberdaya Manusia untuk Perusahaan. Jakarta: Rajawali Pers 